\title{
Continuous Determination of the Oxygen Dissociation Curve for Whole Blood
}

\author{
Luigi Rossi-Bernardi, Massimo Luzzana, Michele Samaja, Mario Davi, \\ Daniela DaRiva-Riccl, Jolanda Minoll, Brian Seaton, ${ }^{1}$ and Robert L. Berger ${ }^{2}$
}

We report here the development of a new method that allows continuous determination of the oxygen dissociation curve for microsamples $(600 \mu l)$ of whole blood under conditions of $\mathrm{pH}, \mathrm{PCO}_{2}$, methemoglobin concentration, and 2,3-diphosphoglycerate content closely approaching those found in the circulatory system. The method consists of gradually oxygenating a blood sample by adding $\mathrm{H}_{2} \mathrm{O}_{2}$ in the presence of catalase (EC 1.11.1.6), to produce the reaction $\mathrm{H}_{2} \mathrm{O}_{2} \rightarrow \mathrm{H}_{2} \mathrm{O}+1 / 2$ $\mathrm{O}_{2}$. Because the total oxygen content of blood can be derived from the known rate of $\mathrm{H}_{2} \mathrm{O}_{2}$ addition and the $\mathrm{PO}_{2}$ is determined in the liquid phase by an oxygen electrode, the two functions (total $\mathrm{O}_{2}$ content) and ( $\%$ oxygen saturation) vs. $\mathrm{PO}_{2}$ are simple to calculate. $\mathrm{PCO}_{2}$ and pH are controlled by adding base simultaneously with the gradual oxygenation of blood. The method described thus avoids the direct measurement of oxygen saturation of whole blood.

Additional Keyphrases: catalase-produced reaction sickle cell anemia - respiratory function of blood

Determination of the oxygen dissociation curve (ODC) under near-physiological conditions is of critical importance in the study of respiratory functions of blood. Although there are several new methods for continuously recording the ODC, few of them include proper attention to the careful control of the various factors that are known to affect the position and the shape of the curve.

We report here the development of a new method that allows continuous determination of the ODC of microsamples $(600 \mu \mathrm{l})$ of whole blood under conditions of $\mathrm{pH}, \mathrm{pCO}_{2}$, methemoglobin concentration, and 2,3-diphosphoglycerate content closely approaching those found in the circulatory system. ${ }^{3}$

\section{Methods}

Principle. The method consists of gradually oxygenating a blood sample by adding $\mathrm{H}_{2} \mathrm{O}_{2}$ in the pres-

\footnotetext{
Cattedra di Enzimologia, University of Milan, Via G. Celoria, 2, 20133 Milan, Italy.

1 Zoological Society of London.

2 Laboratory of Technical Development, National Heart and Lung Institute, National Institutes of Health, Bethesda, Md. 20014. Reprint requests should be directed to this author.

3 The ODC system will be available from Advanced Products, Via Ceradini 14, 20129 Milan (Italy), after September 1, 1975.

Received May 27, 1975; accepted Aug. 13, 1975.
}

ence of catalase (EC 1.11.1.6), to produce the reaction $\mathrm{H}_{2} \mathrm{O}_{2} \rightarrow \mathrm{H}_{2} \mathrm{O}+1 / 2 \mathrm{O}_{2}$. Because the total oxygen content of blood can be derived from the known rate of $\mathrm{H}_{2} \mathrm{O}_{2}$ addition, and the $\mathrm{p}_{2}$ is determined in the liquid phase by an oxygen electrode, the two functions [total $\mathrm{O}_{2}$ content] and [\% oxygen saturation] vs. $\mathrm{pO}_{2}$ are simple to calculate. $\mathrm{pCO}_{2}$ and $\mathrm{pH}$ are controlled by adding base simultaneously with the gradual oxygenation of blood. The method described thus avoids the direct measurement of oxygen saturation of whole blood.

Figure 1 shows the cuvette used for the ODC determination. The sample compartment has a total volume of $1.0 \mathrm{ml}$. The stopper on the top keeps the blood contained in the cuvette under anaerobic conditions and determines the sample volume used in the experiment. This volume can conveniently be varied by removing the spacer between the cuvette and the stopper. Most of the work reported in this paper was done with a cuvette volume of 0.500 or $1.000 \mathrm{ml}$. Commercial $p_{\mathrm{O}_{2}}$ or $\mathrm{pCO}_{2}$ electrodes (Instrumentation Laboratory, S.p.A., Milan/Lexington, Mass. 02173) were used. The cuvette is thermostatted by water circulating from an external, temperature-controlled reservoir. A circular stirring magnet is contained in the cuvette and is magnetically coupled to the dc motor (Figure 1), the speed of which is continuously adjustable by a separate electronic circuit. Stirring speed influences the size of the stagnant layer of liquid (and thus the $\mathrm{pO}_{2}$ readings) around the

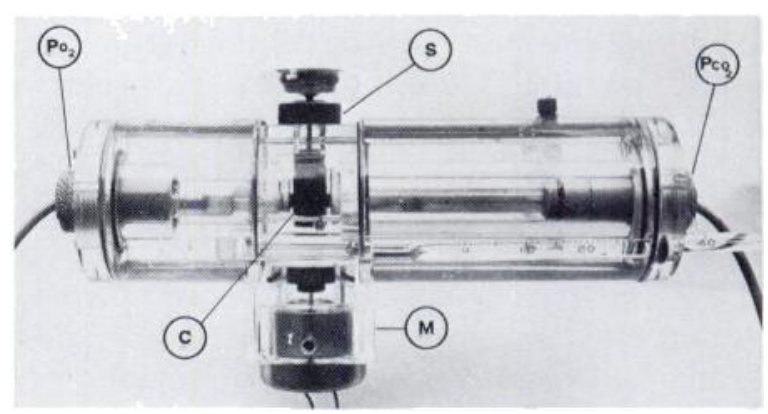

Fig. 1. System used for ODC determining the oxygen dissociation curve

$\mathrm{PO}_{2}$ and $\mathrm{PCO}_{2}$ are the oxygen and carbon dioxide electrodes. $C$ is the cuvette containing the blood, $M$ the motor used for magnetic stirring, and $S$ a spacer 


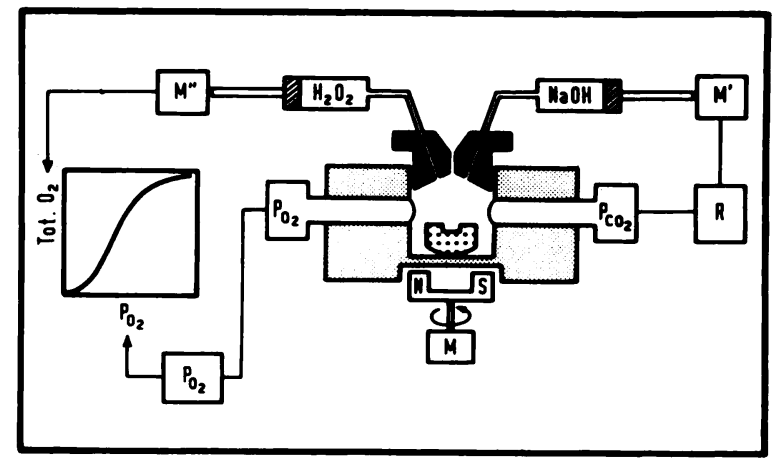

Fig. 2. Block diagram of the complete experimental setup $M$ and $M^{\prime \prime}$ represent two Razel syringe pumps. $R$ is an oloctronic proportional control system for automatically maintaining $\mathrm{PCO}_{2}$ (or pH) constant

$\mathrm{PO}_{2}$ electrode, particularly when a fast-response, highly permeable membrane is used. In the configuration shown in Figure 1 the optimum speed of stirring, above which there is no further change in $\mathbf{p O}_{2}$ reading, is about $600 \mathrm{rpm}$. A Teflon (Du Pont) membrane of $12-\mu \mathrm{m}$ thickness gives the best results in regard to speed and stability. Figure 2 is a block diagram of the complete setup.

$\mathrm{pO}_{2}$ electrolyte solution type S4064 (Radiometer, Copenhagen) was used as a supporting electrolyte in the Instrumentation Laboratory $\mathrm{pO}_{2}$ electrode. $\mathrm{H}_{2} \mathrm{O}_{2}$ (300 g/liter, RSE grade, with no added stabilizer, approximately $8.8 \mathrm{~mol} /$ liter) was obtained from C. Erba (Milan) and diluted to give an approximate $1 \mathrm{~mol} /$ liter stock solution. The exact titer of the peroxide solution was checked by permanganate titration and by Van Slyke gasometric analysis as indicated by Gregory (1). Catalase was obtained from Sigma Chemical Co., St. Louis, Mo. 63178 (bovine liver origin; specific activity, $33000 \mathrm{Sigma}$ units/ml). Of this preparation, $10 \mu \mathrm{l}$ was used per milliliter of blood. The total $\mathrm{H}_{2} \mathrm{O}_{2}$ volume needed for a complete ODC determination depends on the hemoglobin concentration. Typically, 18 to $22 \mu \mathrm{l}$ of $1 \mathrm{~mol} /$ liter $\mathrm{H}_{2} \mathrm{O}_{2}$ is required for determination of the ODC of normal blood. The microsyringes used for adding $\mathrm{H}_{2} \mathrm{O}_{2}$ were of 30- and 100- $\mu$ l capacity. $\mathrm{H}_{2} \mathrm{O}_{2}$ was added to blood at constant speed by a Type A-99 syringe pump (Razel Scientific Instruments, Stamford, Conn. 06907). $\mathrm{H}_{2} \mathrm{O}_{2}$ can be added at a suitable rate by appropriate selection of the 99-speed digital-switch control of the pump and of the size of the microsyringe. We found it convenient to use rates of $\mathrm{H}_{2} \mathrm{O}_{2}$ delivery such as to achieve complete oxygenation of blood in 10,15 , or $20 \mathrm{~min}$. When blood is oxygenated at constant total $\mathrm{CO}_{2}$ content, $p_{\mathrm{CO}_{2}}$ will increase and $\mathrm{pH}$ will decrease. We added base, to keep $\mathrm{pCO}_{2}$ constant, either by manually adding 5 to $10 \mu$ l of $\mathrm{NaOH}$ ( 0.5 mol/liter) from a Gilmont precision micrometer syringe (Cole-Parmer, Chicago, Ill. 60648) or by using a second Razel syringe pump, under computer control. Titration curves for whole blood at constant $p_{\mathrm{CO}_{2}}$ were obtained as described before (2), except that blood was equilibrated in an IL Model 237 tonometer.
The most critical factors in the determination of ODC's were $\mathrm{pO}_{2}$ electrode performance and calibration. High speed of response is desirable if ODC's are to be obtained in $\mathbf{1 0}$ to $\mathbf{1 5} \mathrm{min}$. Response time of the $\mathrm{pO}_{2}$ electrode can be estimated by adding a few microliters of concentrated dithionite solution to the cuvette containing water in equilibrium with air. Half time of response of the $\mathrm{pO}_{2}$ system described here was consistently about 1.0 to $1.5 \mathrm{~s}$. Calibration of the electrode requires careful attention, as a $p_{\mathrm{O}_{2}}$ electrode standardized against a gas phase gives a lower reading when measuring a blood sample in equilibrium with the same $p_{\mathrm{O}_{2}}$. This difference in $p_{\mathrm{O}_{2}}\left(\Delta p_{\mathrm{O}_{2}}\right.$, typically about $5 \%$ of the reading) can be decreased, but not eliminated, by stirring the blood in contact with the electrode. For estimating the $\Delta p_{\mathrm{O}_{2}}$ factor, the stopper on top of the cuvette is raised, to obtain a gas phase over the blood in the cuvette. After equilibration of the blood with air, the sensitive tip of the electrode is exposed to air by aspirating some of the blood. Small droplets of blood occasionally clinging to the membrane are wiped off with tissue paper. The difference in $\mathrm{pO}_{2}$ reading between the gas and the blood is noted and a calibration factor is obtained to correct all $\mathrm{p}_{2}$ readings on blood.

Oxygen capacity at the end of ODC measurement can be ascertained by the simple extrapolation procedure of Duvelleroy et al. (3), by spectrophotometric analysis at various wavelengths as described by Benesch et al. (4) and Van Kampen and Zijlstra (5), or by standard gasometric analysis (6). Methemoglobin concentration at the end of the experiment was estimated by the method of Kilmartin and Rossi-Bernardi (7). 2,3-Diphosphoglycerate concentration was measured by the method of Rose and Liebowitz (8). The output of the $\mathrm{O}_{2}$ and $\mathrm{CO}_{2}$ electrodes is fed into an IL 213 electrometer. The plot of total $\mathrm{O}_{2}$ vs. $p_{\mathrm{O}_{2}}$ is obtained by connecting the output of the $\mathrm{O}_{2}$ amplifier to an $x=f(t)$ recorder. The gain of the recorder is adjusted initially to give a full-scale reading at 80 $\mathrm{mmHg} p_{\mathrm{O}_{2}}$. At higher $p_{\mathrm{O}_{2}}$ values, this gain is reduced by a factor of two to record the upper part of the curve. The start of the recorder is started when the $\mathrm{H}_{2} \mathrm{O}_{2}$ is added.

\section{Experimental Procedure}

\section{Manual Procedure}

Blood volume required for a complete ODC determination (including $\mathrm{pH}$ measurements) is about $\mathbf{1 . 2}$ $\mathrm{ml}$. This volume can be decreased, with minor loss of accuracy, to about $600 \mu \mathrm{l}$ by removing the spacer shown in Figure 1. The blood is first deoxygenated in an IL 237 tonometer by equilibration with a gas phase containing nitrogen plus an appropriate amount of $\mathrm{CO}_{2}$. The $p_{\mathrm{O}_{2}}$ electrode is calibrated as indicated before, whereas the p $_{\mathrm{CO}_{2}}$ electrode is standardized against the $\mathrm{PCO}_{2}$ of the same gas mixture used for deoxygenation. The $\mathrm{pH}$ of deoxygenated blood is measured with a capillary electrode by suction directly from the tonometer. Blood is sampled by a plastic 
syringe previously washed with the same gas mixture flowing from the tonometer, and introduced into the cuvette. The blood is then gradually oxygenated by adding $\mathrm{H}_{2} \mathrm{O}_{2}$ at a suitable rate. In the presence of catalase, the peroxide is very rapidly decomposed to oxygen, which is itself in instantaneous equilibrium with the hemoglobin contained in the erythrocyte. The total amount of oxygen in $\mathrm{ml} / 100 \mathrm{ml}$ and the percentage oxygen saturation of blood $\left(\mathrm{S}_{2}\right)$ are given, at any time $t$, by the approximate equations 1 and 2:

$$
\text { Total } \mathrm{O}_{2(t)}=2240 \times \frac{V_{\mathrm{H}_{2} \mathrm{O}_{2}(t)} \times 1 / 2\left[\mathrm{H}_{2} \mathrm{O}_{2}\right]}{V_{0}}
$$

where $V_{0}=$ cuvette volume $(l)$, $V_{\mathrm{H}_{2} \mathrm{O}_{2}(t)}=$ volume of $\mathrm{H}_{2} \mathrm{O}_{2}$ added at time $t$ in $V_{0}(l)$, $\left[\mathrm{H}_{2} \mathrm{O}_{2}\right]=$ concentration of hydrogen peroxide $(\mathrm{mol} /$ l); and

$$
\mathrm{S}_{\mathrm{O}_{2}(t)}=100 \frac{V_{\mathrm{H}_{2} \mathrm{O}_{2}(t)} \times 1_{2}\left[\mathrm{H}_{2} \mathrm{O}_{2}\right]-\left(p_{\mathrm{O}_{2}(t)} V_{0 \alpha}\right)}{C}
$$

where $\alpha$ is the coefficient of oxygen solubility in blood and $C$ the oxygen capacity. As the peroxide delivery system is linear with time $\left(V_{\mathrm{H}_{2} \mathrm{O}_{2}}=\mathrm{kt}\right)$ and $p_{\mathrm{O}_{2}}$ is continuously measured, total $\mathrm{O}_{2}$ and $\mathrm{S}_{\mathrm{O}_{2}}$ can be simply calculated from the above equations.

The equations are valid only if an accuracy of $\pm 1 \%$ to $2 \%$ oxygen saturation is required, as in most clinical applications. If more precise determinations are needed, the following points should be considered.

(i) In Equations 1 and 2 it is assumed that the initial blood saturation is zero. In fact, it is convenient to hold the deoxygenation time in the tonometer to no longer than 18 to $20 \mathrm{~min}$, thus avoiding significant changes in the 2,3-diphosphoglycerate concentration of the original sample. After this time a residual 1 to $2 \%$ oxygen saturation is usually found. The final part of the function (total $\mathrm{O}_{2}$ ) vs. $p_{\mathrm{O}_{2}}$ can be obtained by extrapolation to $p_{\mathrm{O}_{2}}=0$, as suggested by Maas et al. (9), or by estimating the residual oxygen content by direct manometric analysis.

(ii) Oxygen capacity can be obtained at the end of the experiment by the simple extrapolation procedure of Duvelleroy et al. (3), which is only valid if $\mathrm{pO}_{2}$ values exceeding 350 to $400 \mathrm{mmHg}$ can be reached. It is not valid to reach such values by adding $\mathrm{H}_{2} \mathrm{O}_{2}$, as it has been found that some small gas bubbles occasionally are liberated from the solution at $p_{\mathrm{O}_{2}}$ 's greater than $150 \mathrm{mmHg}$. Thus, for accurate results, it is advisable to first obtain oxygen saturation when $p_{\mathrm{O}_{2}}$ has reached 100 to $150 \mathrm{mmHg}$. This is done by using the micromethod of Rossi-Bernardi et al. (10), which requires only $20 \mu \mathrm{l}$ of whole blood.

(iii) Effect of dilution. It should be recalled that introduction of the peroxide and of $\mathrm{NaOH}$ into the cuvette (with a fixed volume $V_{0}$ ) will cause a small but significant dilution of blood. A -more exact expression for the oxygen saturation at any time $(t)$ can be obtained from the following considerations. At time $t=0$, the total oxygen content, $\mathrm{O}_{2}$ tot, is practi- cally determined by the residual saturation, $S_{0}$, of the sample, as the dissolved oxygen can be considered negligible. Thus,

$$
\mathrm{O}_{2 \operatorname{tot}(t=0)}=\mathrm{G}=2240\left(\mathrm{~S}_{0} \times \mathrm{C} \times V_{0}\right) \mathrm{ml} / 100 \mathrm{ml}
$$

The addition of a constant volume of $\mathrm{H}_{2} \mathrm{O}_{2}\left(\mathrm{~V}_{\mathrm{H}_{2} \mathrm{O}_{2}}\right)$ and $\mathrm{NaOH}\left(V_{\mathrm{NaOH}}\right)$ in a unit interval of time will displace a corresponding volume of blood from the reaction chamber (Figure 1). The total oxygen present in the cuvette at time $t=1$ will then be given by

$$
\mathrm{O}_{2 \operatorname{tot}(t=1)}=\mathrm{KO}_{2 \operatorname{tot}(t=0)}+Q_{\mathrm{O}_{2}}
$$

where $Q_{\mathrm{O}_{2}}=1_{2}\left[\mathrm{H}_{2} \mathrm{O}_{2}\right] V_{\mathrm{H}_{2} \mathrm{O}_{2}}$, and $\mathrm{K}=V_{0} /\left[V_{0}+\right.$ $V_{\mathrm{H}_{2} \mathrm{O}_{2}}+V_{\mathrm{NaOH}}$. At time $t=i$

$$
\mathrm{O}_{2 \operatorname{tot}(t=i)}=\mathrm{K}^{i}(G-D)+D
$$

where

$$
D=\frac{Q_{\mathrm{O}_{2}}}{1-\mathrm{K}}
$$

In a similar way the oxygen capacity at any given time $t=i$ is given by

$$
C_{i}=C_{0} \times \mathrm{K}^{i}
$$

and $\mathrm{S}_{\mathrm{O}_{2}}$ by

$$
\mathrm{S}_{\mathrm{O}_{2}}=\frac{\mathrm{K}^{i}(G-D)+D}{C_{0} \times K^{i}}
$$

Since the total dilution of blood at the end of the ODC determination is only about $2 \%$, equation 3 represents a convenient and yet simple approximation for the calculation of $\mathrm{S}_{\mathrm{O}_{2}}$.

(iv) Oxygen consumption by the blood. Blood, like all living tissues, consumes oxygen. The change in $p_{\mathrm{O}_{2}}$ of samples of completely oxygenated blood, at 37 ${ }^{\circ} \mathrm{C}$, is about $2.7 \mathrm{mmHg} / \mathrm{min}$ (11). This corresponds to an oxygen consumption of about $3.8 \times 10^{-3} \mathrm{mmol}$ of oxygen per liter. The time required for determining a complete ODC by the present method, once the blood has been transferred from the tonometer to the cuvette, is about $15 \mathrm{~min}$, so not more than $5.7 \times 10^{-2}$ mmol of oxygen per liter will be consumed. This is a negligible quantity (i.e., about $\mathbf{0 . 5 \%}$ ) compared to the normal total oxygen present in solution at the end of the ODC determination. However, if the oxygen consumption of whole blood is substantially increased, as found in samples with an increased number of leukocytes or with heavy bacterial contamination, the oxygen consumption of blood will have more pronounced effects on the ODC. The rate of oxygen consumption of blood may be easily deduced at the end of an ODC determination (at $p_{\mathrm{O}_{2}}>130 \mathrm{mmHg}$ ) by noting the rate of change in $\mathrm{pO}_{2}$ with time.

\section{Computer-Operated Procedure}

Hardware. Complete analysis of the ODC according to the more exact principles outlined in (iii) above usually requires much desk work. Especially when repeated determinations of the ODC under varied conditions are needed, a computer-operated pro- 


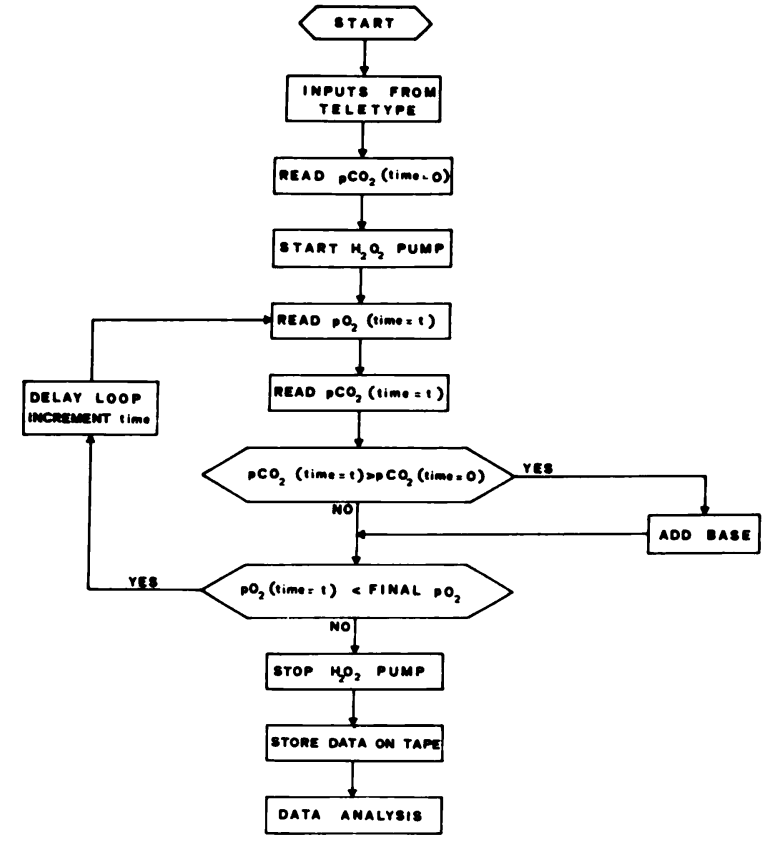

Fig. 3. A flow diagram for operating the system shown in figure 2 under computer control

cedure allows an almost simultaneous analysis of the data, on-line with the experiment. A complete computer-operated system has thus been built around a PDP8/e minicomputer (Digital Equipment Corp., Maynard, Mass. 01754). The hardware of the complete system, which will only be briefly described, consists of a type MFE 815 Plotamatic X-Y recorder (MFE, Salem, N. H. 03079) computer interfaced for curve plotting, a digital multimeter type 2440 (Data Precision, Wakefield, Mass. 01880), and a specially developed interface. The interface provides the control of the two Razel syringe pumps (one for addition of $\mathrm{H}_{2} \mathrm{O}_{2}$ and the other for addition of base), the multiplexing of the analog output of the $p_{\mathrm{O}_{2}}$ and $p_{\mathrm{CO}_{2}}$ channels of the IL 213 electrometer, and the transmission (as ASC II characters at 4800 baud) of $p_{\mathrm{O}_{2}}$ and $p_{\mathrm{CO}_{2}}$ readings from the multimeter to a $\mathrm{KL} 8 \mathrm{JA}$ interface card in the computer.

Software. The program is written in FORTRAN II under OS8. Figure 3 shows a flowsheet. The program takes less than $4 \mathrm{~K}$ bytes of memory and provides a digital printout on a teletype of $(a)$ total oxygen output and percent saturation vs. $p_{\mathrm{O}_{2}},(b) \mathrm{P}_{50}$ value, (c) the value of Hill's function between 30 and $70 \%$ saturation, and $(d)$ the value of $\eta$, the "Hill coefficient." The program also provides an analog output on the $\mathrm{X}-\mathrm{Y}$ recorder of the same functions. Complete details on the hardware and software of the computer operated system are available on request.

\section{Results}

Figure 4 shows the interrelationship, at $37^{\circ} \mathrm{C}$, between $p_{\mathrm{CO}_{2}}$ and $\mathrm{pH}$ in whole human blood, in the oxy- and deoxygenated state, at various total $\mathrm{CO}_{2}$ contents. Figure 5 shows an ODC for fresh human blood as obtained by the method herein described

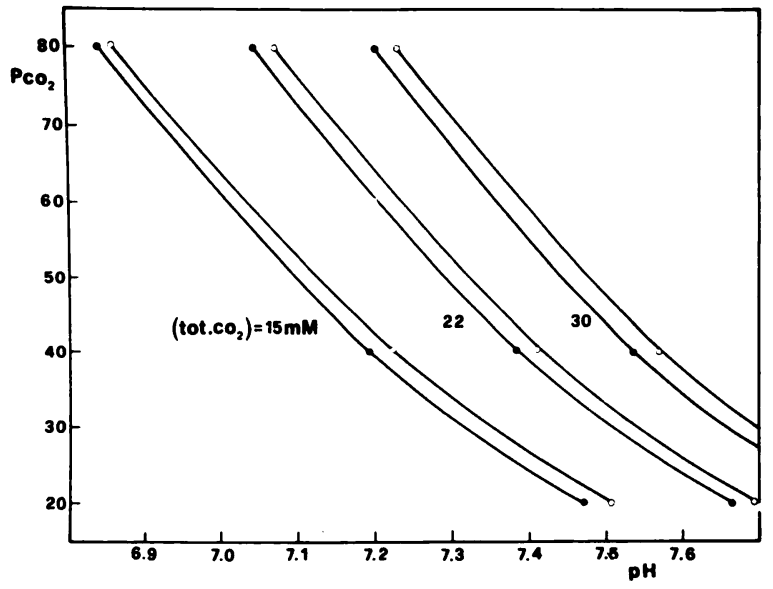

Fig. 4. $\mathrm{pCO}_{2}$ vs. $\mathrm{pH}$ curves for human blood at $37^{\circ} \mathrm{C}$ under varied total $\mathrm{CO}_{2}$ content

$0=$ oxy blood, $O=$ deoxy blood

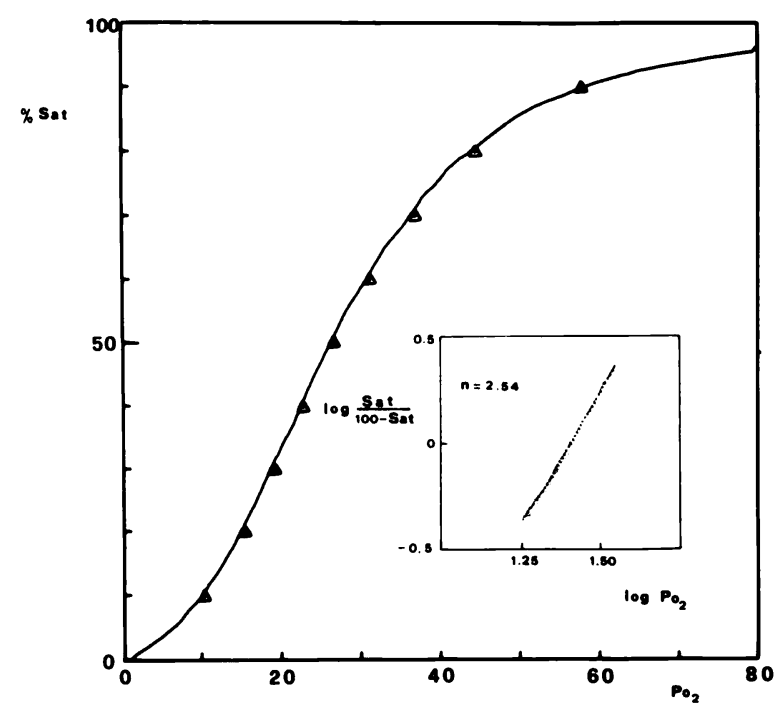

Fig. 5. Oxygen dissociation curve for a sample of freshly drawn normal human blood at $37^{\circ} \mathrm{C}, \mathrm{PCO}_{2}=40 \mathrm{mmHg}, \mathrm{pH}=$ 7.4

The continuous line refers to the ODC determined by the method described in this paper, whereas individual points are the results of microgasometric anatysis. The insert shows a plot of the data of the main figure according to Hall's equation. The $n$ value equals 2.54

(continuous line). The experimental points refer to actual gasometric determinations of $\mathrm{S}_{\mathrm{O}_{2}}$ by the Van Slyke gasometric technique. Figure 6 shows the ODC obtained for a single blood sample in a total time interval (from right to left) of 10,15 , and $20 \mathrm{~min}$. The three curves (almost superimposed) are well within experimental error. Figure 7 shows a typical plot of the total oxygen content vs. $p_{\mathrm{O}_{2}}$ of normal blood and of blood obtained from a homozygous sickle cell patient. Figure 8 shows the concentrations of 2,3-diphosphoglycerate and methemoglobin during the complete procedure required for the determination of ODC.

\section{Discussion}

The position and the shape of the ODC for human blood is affected not only by temperature, $\mathrm{pH}$, ionic 


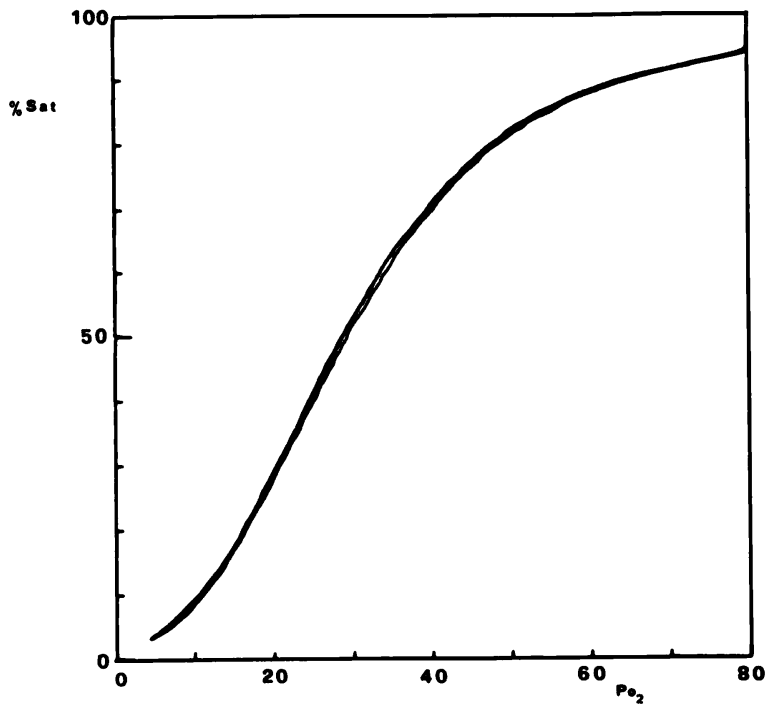

Fig. 6. Oxygen dissociation curves for normal human blood at $37^{\circ} \mathrm{C}, \mathrm{PCO}_{2}=40 \mathrm{mmHg}, \mathrm{pH}=7.4$, determined by the meth od described in this paper in a total oxygenation time (right to left) of 10,15 , and $20 \mathrm{~min}$

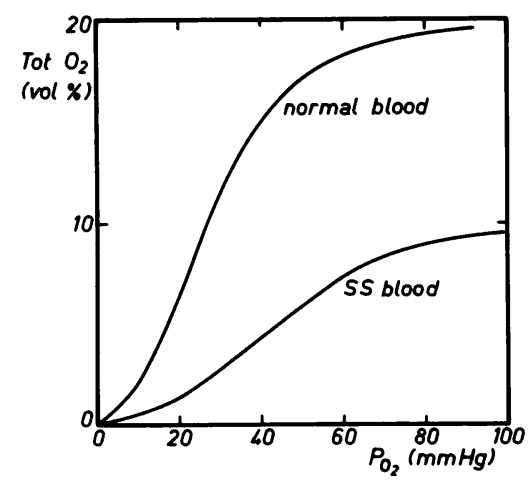

Fig. 7. The oxygen dissociation curve, at $\mathrm{PCO}_{2}=40 \mathrm{mmHg}, t$ $=37^{\circ} \mathrm{C}, \mathrm{pH}=7.4$ (reproduced as total $\mathrm{O}_{2}$ vs. $\mathrm{po}_{2}$ ) for normal blood and blood obtained from a homozygous sickle cell anemia patient

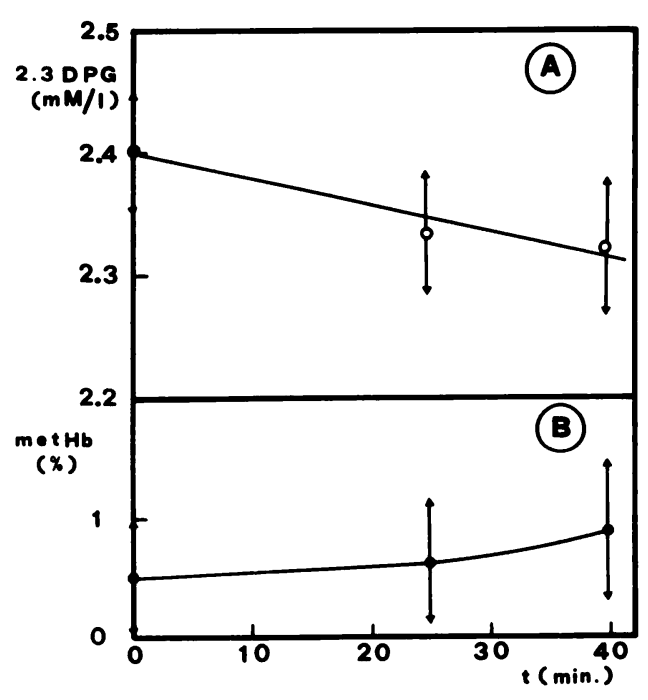

Fig. 8. The decrease in 2,3-diphosphoglycerate (in millimoles per liter of whole blood) and the increase in methemoglobin content of normal blood at $\mathrm{PCO}_{2}=40 \mathrm{mmHg}, t=37^{\circ} \mathrm{C}, \mathrm{pH}$ $=7.4$, during the time required for an oxygen dissociation curve determination

The arrows represent the standard error of the method of analysis strength, and carbonmonoxyhemoglobin or methemoglobin concentration, but also by changes of $\mathrm{pCO}_{2}$ at constant $\mathrm{pH}$, and by variations in the concentration of labile phosphorylated intermediates of erythrocyte metabolism, such as 2,3-diphosphoglycerate and ATP. Thus the determination of the ODC of whole blood under near-physiological conditions requires careful control of several variables if meaningful information is to be derived from the experimental data.

In very few of the methods so far described, however, has proper attention been paid to changes in the oxygen affinity and in the shape of the ODC induced by the experimental procedure. Methods for ODC determination can basically be classified as discontinuous if individual points of either of the two functions $\left(\mathrm{O}_{2}\right.$ saturation or total $\mathrm{O}_{2}$ content $)=f\left(p_{\mathrm{O}_{2}}\right)$ are obtained, and continuous if the same functions are continuously recorded. In this discussion we focus particularly on the latter approach.

Continuous methods can be further classified as open methods if the blood is in direct contact with a gas phase, or closed (or all-liquid) methods if only a liquid phase is present. The best examples of the continuous open method are probably those outlined for hemoglobin solutions by Imai et al. (12) and for whole blood by Duvelleroy et al. (3). To speed up the equilibration time, the system in both cases is operated under nonequilibrium conditions between the gas and the liquid phase, increasing the oxygen gradient and the speed of the oxygenation reaction. There are a few critical points to be considered in the approach of Duvelleroy et al.: $(a)$ the procedure requires 5 to $10 \mathrm{ml}$ of blood (10 times more than the method described here) and more than one hour, and (b) the ODC cannot be run at constant $p_{\mathrm{CO}_{2}}$ and/or $\mathrm{pH}$ because of the finite size of the gas compartment over the blood. Thus Duvelleroy et al. report a positive change in $p_{\mathrm{CO}_{2}}$ of about $6 \mathrm{mmHg}$ and a negative change in $\mathrm{pH}$ of about $0.08 \mathrm{pH}$ units in going from the deoxy to the oxy state, whereas it is well known that under physiological conditions changes in $\mathrm{p}_{\mathrm{CO}_{2}}$ and $\mathrm{pH}$ run in opposite directions (13). Experimental data obtained by the procedure of Duvelleroy et al. thus require suitable correction if exacting studies on the functional properties of blood are to be carried out. Maas et al. (9) have described an automatic data-acquisition and -correction system by computer analysis, in which the approach of Duvelleroy et al. is used, but unfortunately the correction factors used (such as the Bohr coefficient d $\log p_{\mathrm{O}_{2}} / \mathrm{d} \mathrm{pH}$ ) are themselves functions of the degree of oxygen saturation, 2,3-diphosphoglycerate content, $p_{\mathrm{CO}_{2}}$, etc.

Continuous closed methods usually take less time than open methods. However, oxygenation of hemoglobin in presence of $\mathrm{CO}_{2}$ in a closed system causes a large change in $\mathrm{p}_{2}$ and $\mathrm{pH}$. The approach of Colman and Longmuir (14) may represent the first example of the ODC determination in an all-liquid system. In their method the blood is oxygenated and the 
oxygen present in solution (combined plus dissolved) is then used up at a constant rate by adding a heartmuscle preparation, while the $\mathrm{pO}_{2}$ is continuously monitored by polarographic methods. Although further improvements of this method have been proposed (15), the whole approach has not yet been evaluated quantitatively. The main criticism is one common to all closed methods: they do not allow for $\mathrm{pH}$ and $\mathrm{PCO}_{2}$ control along the ODC.

The method of Kiesow et al. (16) is another example of the continuous closed system. Here the blood is diluted with isotonic buffers, saline, or Krebs-Ringer bicarbonate solutions and then completely deoxygenated. The suspension is gradually oxygenated by generating oxygen by the catalytic decomposition of $\mathrm{H}_{2} \mathrm{O}_{2}$, while the oxygen saturation is continuously monitored in a dual-wavelength spectrophotometer. Dilution of blood with buffers or other solutions of definite electrolyte content minimizes changes of $\mathrm{pCO}_{2}$ and $\mathrm{pH}$ during oxygenation, but unfortunately also alters the pre-existing conditions of $\mathrm{pH}$ and of the Donnan equilibrium of the original sample. As the hematocrit, $\mathrm{PCO}_{2}, \mathrm{pH}$, and distribution of electrolytes between plasma and erythrocyte may be far from normal in many pathological conditions, dilution of abnormal samples with saline solutions of normal osmolarity may alter their original properties. For instance, large changes in oxygen affinity have been reported for sickle cell erythrocytes with various intracellular concentrations of hemoglobin (17). Kiesow et al. (18) recently proposed another ingenious method for determination of the ODC of hemoglobin solutions, by using liquid fluorocarbon as the oxygentransporting system. This approach, which would avoid some of the difficulties outlined above, may find interesting applications in the study of whole blood.

The preceding discussion, although not complete, points out the main practical and theoretical difficulties in the various experimental approaches to determination of the ODC for whole blood. The main problem in an all-liquid system is the significant change in $\mathrm{pH}$ and $\mathrm{pCO}_{2}$ caused by the liberation of Bohr protons upon oxygenation and by the presence of "oxygen-linked" carbamate compounds of $\mathrm{CO}_{2}$ with hemoglobin. The interrelationship between $p_{\mathrm{CO}_{2}}$ and $\mathrm{pH}$ for human oxygenated and deoxygenated blood at $37^{\circ} \mathrm{C}$ at constant total $\mathrm{CO}_{2}$ is shown in Figure 4. ODC's at constant $\mathrm{pH}$ and $\mathrm{pCO}_{2}$ are ideally required for theoretical studies on the effect of various allosteric ligands on the oxygen affinity of blood or hemoglobin solutions (19). As more $\mathrm{CO}_{2}$ is contained in deoxy blood than in oxy blood, the determination of the ODC at constant $\mathrm{pH}$ and $\mathrm{pCO}_{2}$, starting from the deoxy end of the curve, would require the removal of some $\mathrm{CO}_{2}$. This is experimentally unfeasible in a closed system. The only practical way to obtain an ODC at constant $\mathrm{pH}$ and $p_{\mathrm{CO}_{2}}$ would then be to run the curve from the oxy toward the deoxy end, while the total $\mathrm{CO}_{2}$ content is simultaneously increased by addition of bicarbonate or carbonate solutions. This approach would require adopting a suitable reaction for progressively decreasing the total oxygen present in solution. Several oxygen-consuming reactions (e.g., oxidation of glucose to gluconic acid, catalyzed by glucose oxidase; oxidation of ascorbic to dehydroascorbic acid, catalyzed by ascorbic oxidase) have been extensively tried for this purpose (Rossi-Bernardi and Luzzana, unpublished work), but no practical solution has yet been found.

Only two conditions are then left under which to determine the ODC, starting with completely deoxygenated blood: $(a)$ at constant total $\mathrm{CO}_{2}$ content and constant $p_{\mathrm{CO}_{2}}$, at various $\mathrm{pH}$ values, and (b) at constant total $\mathrm{CO}_{2}$ and $\mathrm{pH}$, but various $\mathrm{p}_{\mathrm{CO}_{2}}$ values. Both conditions can be attained by the addition of base to the system, simultaneously with the progressive oxygenation of hemoglobin. Figure 4 shows that, for normal blood, in the $p_{\mathrm{CO}_{2}}$ range 20 to $80 \mathrm{mmHg}$, the total $\mathrm{pH}$ change between deoxy and oxy blood is no greater than $0.04 \mathrm{pH}$ unit. If, on the other hand, total $\mathrm{CO}_{2}$ content and $\mathrm{pH}$ are kept constant, the $\mathrm{p}_{\mathrm{CO}_{2}}$ change is only 3 to $4 \mathrm{mmHg}$. For case $a$ the change in $\mathrm{pH}$ is close to that found in the circulatory system. This condition may thus be preferred if data mainly of clinical or physiological interest are required. If, however, only a minimum manipulation of the data is desired, condition $b$ is preferred, because a $\mathrm{pCO}_{2}$ change of 3 to $4 \mathrm{mmHg}$ at constant $\mathrm{pH}$ has only a negligible effect on oxygen affinity (less than $1 \%$ of the value of $\left.P_{50}\right)$. The system shown in Figure 1 can easily be adapted to the determination of ODC at constant $\mathrm{pH}$ simply by using a $\mathrm{pH}$ electrode instead of the $\mathrm{PCO}_{2}$ electrode.

The control experiments reported in Figure 8 show that $(a)$ the concentration of organic phosphates is not significantly decreased in the time required (30 min) for a complete ODC determination, and $(b)$ only a very slight amount of methemoglobin is formed during the gradual oxygenation by the peroxide. No differences were found in the ODC's determined in 10,15 , and $20 \mathrm{~min}$ by changing the rate of the hydrogen peroxide addition. This means that the system essentially operates under equilibrium conditions. The automatic data-acquisition system briefly described and the possibility of analyzing the ODC online with the experiment make this system ideally suited for the extensive analysis of the effect of temperature, $\mathrm{pH}, \mathrm{pCO}_{2}$, organic phosphate, and other variables on the position and shape of the oxygen dissociation curve.

An example of a pathological case is shown in Figure 7. the striking effect of the presence of anemia and sickle cell hemoglobin on the oxygen-transporting properties of blood is clearly apparent. The technique described should be very useful in the study of functional properties of blood. For example, a complete characterization of the effect of variation of $\mathrm{pH}$, $p_{\mathrm{CO}_{2}}$, 2,3-diphosphoglycerate, and base excess on the ODC of an homozygous sickle cell patient can be ob- 


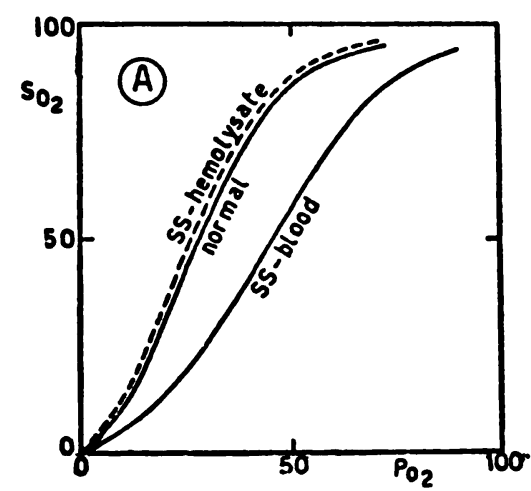

Fig. 9. The oxygen dissociation curve for normal blood and for sickle cell blood and hemolysate

$\mathrm{PCO}_{2}=4 \mathrm{mmHtg}, \mathrm{pH}=7.4,37^{\circ} \mathrm{C}$

tained in one day, with use of a total of $14 \mathrm{ml}$ of whole blood (20).

Figure 9 shows the ODC of normal and sickle cell blood at $p_{\mathrm{CO}_{2}}=40 \mathrm{mmHg}, \mathrm{pH}$ about 7.4. The two curves have been represented as percent saturation. A separate series of experiments shown in Figures 5 and 6 demonstrates that the curves of Figure 9 truly represent equilibrium conditions. The experiments involved equilibration of completely oxygenated SSblood with various partial pressures of oxygen in a microtonometer for $30 \mathrm{~min}$, followed by measurement of total oxygen by a micromanometer technique. It is remarkable to find that up to the high $\mathrm{O}_{2}$ saturation range investigated (about 96\%), the value of $\eta$ (the "Hill coefficient," 12) seems to be identical for SS and normal blood while the $\mathrm{P}_{50}$ of sickle-cell whole blood is shifted greatly to the right. The ODC of sickle cell hemolysate (broken line of Figure 9), obtained by freezing and thawing a sample of SS-blood, is seen to be very close to the ODC of normal whole blood. This suggests that some caution should be used with ODC and $P_{50}$ methods where the blood is hemolyzed before measurement, if done anaerobically. A full clinical study of this point is presently under way.

This study was supported in part by USPHS Grant No. HL15613 and by the Consiglio Nazionale delle Ricerche (Rome). One of us (B. S.) is grateful to the European Molecular Biology Organization for a short-term fellowship. R. L. B. thanks the National Science Foundation for travel support under Italy-U.S. Cooperative Science Program No. P-86.

\section{References}

1. Gregory, I. C., Assessment of Van Slyke manometric measurements of oxygen content. J. Appl. Physiol. 34, 715 (1973).

2. Rossi-Bernardi, L., and Roughton, F. J. W., The specific influence of carbon dioxide and carbamate compounds on the buffer power and Bohr effect in human haemoglobin solutions. J. Physiol. (London) 189, 1 (1967).

3. Duvelleroy, M. A., Buckles, R. G., Rosenkaimer, S., Tung, C., and Laver, M. B. An oxyhemoglobin dissociation analyser. J. Appl. Physiol. 28, 227 (1970).

4. Benesch, R. E., Benesch, R., and Yung, S., Equations for the spectrophotometric analysis of hemoglobin mixtures. Anal. Biochem. 55, 245 (1973).

5. Van Kampen, E. J., and Zijlstra, W. G., Determination of hemoglobin and its derivatives. Adv. Clin. Chem. 8, 141 (1965).

6. Van Slyke, D. D., and Plazin, J., Micromanometric Analyses. The Williams and Wilkins Co., Baltimore, Md., 1961.

7. Kilmartin, J. V., and Rossi-Bernardi, L., The binding of carbon dioxide by horse hemoglobin. Biochem. J. 124, 31 (1971).

8. Rose, Z. B., and Liebowitz, J., Direct determination of 2,3-diphosphoglycerate. Anal. Biochem. 35, 177 (1970).

9. Maas, A. H. J., Hamelink, M. L., van Poelgeest, R., et al., Automatic acquisition and computation of data from the Radiometer dissociation curve analyser. Comp. Prog. Biomed. 4, 93 (1974).

10. Rossi-Bernardi, L., Perrella, M., and Raffaele, I., Micro Blood Analyzer Manual. Advanced Products, Via Ceradini 14, 20129, Milan, Italy.

11. Lenfant, C., and Ancutt, C., Oxygen uptake and change in carbon dioxide tension in human blood stored at $37^{\circ}$. J. Appl. Physiol. 20, 503 (1965).

12. Imai, K., Morimoto, H., Kotani, M., et al., I. An improved method for automatic measurement of the oxygen equilibrium curve of hemoglobin. Biochim. Biophys. Acta 200, 189 (1970).

13. Davenport, H. W., The ABC of Acid-Base Chemistry. The University of Chicago Press, Chicago, Ill., 1969.

14. Colman, C. H., and Longmuir, S., A new method for registration of oxyhemoglobin dissociation curves. J. Appl. Physiol. 18, 420 (1963).

15. Longmuir, I. S., and Chow, J., Rapid method for determining effects of agents on oxyhemoglobin dissociation curves. J. Appl. Physiol. 28, 343 (1970).

16. Kiesow, L. A., Bless, J. W., Nelson, D. P., and Shelton, J. B., A new method for the rapid determination of oxygen dissociation curves in small blood samples by spectrophotometric titration. Clin. Chim. Acta 41, 123 (1972).

17. May, A., and Huehns, R. E., The concentration dependence of the oxygen affinity of $\mathrm{Hb}-\mathrm{S}$. First National Symposium on Sickle Cell Disease, DHEW Publication, NIH No. 75-723, Washington, D. C., 1974 .

18. Kiesow, L. A., Shelton, J. B., Bless, J. W., The determination of $\mathrm{O}_{2}$-dissociation curves in hemoglobin solutions with a liquid flurocarbon $\mathrm{O}_{2}$-transport system. Anal. Biochem. 88, 14 (1974).

19. Kilmartin, J. V., and Rossi-Bernardi, L., Interaction of hemoglobin with hydrogen ions, carbon dioxide and organic phosphates. Physiol. Rev. 53, 836 (1973).

20. Rossi-Bernardi, L., Rossi, F., Luzzana, M., et al., Physiological properties of sickle cell hemoglobin, sickle cell blood, and the effect of carbamylation. First National Symposium on Sickle Cell Disease, DHEW Publication, NIH No. 75-723, Washington, D. C., 1974, p 61. 